\title{
A Design Exploration of Health-Related Community Displays
}

DANIEL GOOCH and BLAINE A. PRICE, School of Computing and Communications, The Open University, UK

ANNA KLIS-DAVIES and JULIE WEBB, Community Action: MK, UK

The global population is ageing, leading to shifts in healthcare needs. It is well established that increased physical activity can improve the health and wellbeing of many older adults. However, motivation remains a prime concern. We report findings from a series of focus groups where we explored the concept of using community displays to promote physical activity to a local neighborhood. In doing so, we contribute both an understanding of the design space for community displays, as well as a discussion of the implications of our work for the broader CSCW community. We conclude that our work demonstrates the potential for developing community displays for increasing physical activity amongst older adults.

CCS Concepts: • Human-centered computing $\rightarrow$ Empirical studies in collaborative and social computing.

Additional Key Words and Phrases: Personal Informatics, Digital Civics, Community Design, Physical Activity

ACM Reference Format:

Daniel Gooch, Blaine A. Price, Anna Klis-Davies, and Julie Webb. 2021. A Design Exploration of HealthRelated Community Displays. Proc. ACM Hum.-Comput. Interact. 5, CSCW1, Article 85 (April 2021), 22 pages. https://doi.org/10.1145/3449159

\section{INTRODUCTION}

Older adults can face multiple age-related health challenges. In the UK, obesity is a grave concern with $42 \%$ of older adults ${ }^{1}$ deemed to be overweight and $26 \%$ classed as being obese [51]. The UK National Health Service (NHS) notes that obesity can lead to an increased risk of diabetes, coronary heart disease, some forms of cancer and stroke. Obesity in older adults is also associated with a number of mental health challenges, particularly reduced feelings of quality of life, life satisfaction, and depressive symptoms [34].

In addition to the impact on the individual, treating obesity and obesity-related conditions is expensive. Across the UK population, in 1998 the total cost was around $£ 2.58$ billion. In 2015 , it was believed to be around $£ 19.50$ billion; by 2050 , it is estimated to reach $£ 22.90$ billion [2].

One approach to reducing the risk of obesity is to promote regular physical activity [52]. Exercise has multiple health benefits; improving physiological function and improving mental wellbeing [48]. Increasing physical exercise amongst older adults not only improves physical health but also reduces feelings of social isolation and improves their mental health [29].

\footnotetext{
${ }^{1}$ Following Age UK and NHS guidelines, we define older adults as being over 60 years old.
}

Authors' addresses: Daniel Gooch; Blaine A. Price, School of Computing and Communications, The Open University, The Open University, Milton Keynes, UK; Anna Klis-Davies; Julie Webb, Community Action: MK, Milton Keynes, UK.

Permission to make digital or hard copies of all or part of this work for personal or classroom use is granted without fee provided that copies are not made or distributed for profit or commercial advantage and that copies bear this notice and the full citation on the first page. Copyrights for components of this work owned by others than the author(s) must be honored Abstracting with credit is permitted. To copy otherwise, or republish, to post on servers or to redistribute to lists, requires prior specific permission and/or a fee. Request permissions from permissions@acm.org.

(c) 2021 Copyright held by the owner/author(s). Publication rights licensed to ACM.

2573-0142/2021/4-ART85 \$15.00

https://doi.org/10.1145/3449159

Proc. ACM Hum.-Comput. Interact., Vol. 5, No. CSCW1, Article 85. Publication date: April 2021. 
Research shows that tracking health through technology can lead to increased activity [53, 55]. However, the evidence for the efficacy of digital activity trackers for increasing activity amongst older adults is still emerging [45]. Some researchers have questioned the current design of the technology, arguing that a variety of design factors limit their acceptability to older adults [57].

Furthermore, the main body of research into health tracking using technology has focussed on the individual. This is clearly important but disregards the impact of social factors on physical activity. For example, approximately half of people who start exercise programmes will dropout within the first six months $[15,36]$ whereas reviews of community-based group exercise for older adults have shown adherence rates of around 70\%-75\% [17, 73]. Such figures demonstrate the importance of community in supporting older adults to undertake physical activity; something that many digital activity trackers do not support. Those that do provide a social element (e.g. Strava), focus on a curated social network rather than an open community-based framing.

We wanted to explore the design possibilities of using digital activity trackers in a community setting. We took inspiration from research into community displays that has demonstrated that they can be effective in changing behaviours and bringing communities together [70]. We therefore have focussed on supplementing existing activity trackers with a community display.

In exploring this design space we can better understand what factors make a difference with regards to the efficacy of public displays for impacting community-level health and what could motivate whole communities to increase their activity. We draw on this analysis to discuss the implications for the broader CSCW community of moving towards a more community-centric approach to health.

We conducted 4 focus group workshops with 25 older adults. We contribute an exploration of the limits of acceptability within the design space of community displays for physical activity. We argue that our results provide a strong foundation for supporting the design of platforms for evaluation in the field.

\section{LITERATURE REVIEW}

Health tracking technology has become hugely popular amongst the population as a whole. One of the largest health tracking technology companies, Fitbit, reported revenue of \$314 million in the second quarter of $2019^{2}$. What evidence is there for the efficacy of this technology?

Some small-scale randomized clinical trials have indicated that the use of health trackers can lead to an increase in step count (e.g. [13,55]). Lim et al., have analysed data from the national-scale intervention program "National Steps Challenge" organized by the Singapore Health Promotion Board. Running from 1 October 2015 to 8 May 2016, participants were offered a free activity tracker and mobile app to track their daily step count, coupled with a structured incentive scheme [42]. Their research focuses on analysing the daily step counts of 140,000 individuals. While their contribution focusses more on the analysis techniques they developed, they also note that while the technology helped some user groups, overweight users generally had a lower adherence than average and non-notable change in steps level [42].

Beyond efficacy, the HCI community has also studied a variety of behavioural factors around health tracking, particularly the adoption, engagement and abandonment of trackers (e.g. [3, 24, 26, $37,77]$ ), suggesting that the current design of tracking technology is only appropriate for certain populations.

\footnotetext{
${ }^{2}$ https://investor.fitbit.com/press/press-releases/press-release-details/2019/Fitbit-Reports-Second-Quarter-Results-for-theThree-Months-Ended-June-29-2019/default.aspx
} 
Given the potential of self-tracking to aid with health outcomes amongst older adults, it is unsurprising that there has been a great deal of interest in exploring both the efficacy and important design characteristics of self-tracking technology specifically designed for or used by older adults.

\subsection{Self-tracking and older adults}

In the USA, survey data indicates that while older adults use health-related self-tracking behaviours more than any other age group, they rarely use self-tracking technology [18]. Given that there is a widespread belief that self-tracking technology can help improve outcomes, a variety of studies have explored older adults' attitudes towards and usage of this technology, to better understand the gap between expectation and reality.

Caldeira et al. explored self-tracking behaviour amongst older adults through eight qualitative interviews [10]. Noting that the majority of respondents did not use technology, they also found that older adults were more focussed on identifying changes in health rather than in making targeted improvement. This suggests they are looking to the tracking technology as a diagnostic aid, rather than as a motivating tool. Caldeira et al. concluded that involving older adults in the design process is essential to ensure that the tools developed are designed to meet their needs.

In a substantial field trial with 95 participants using activity trackers over 10-weeks, McMahon et al. found that questionnaire responses indicated that their participants perceived self-monitoring technology for physical activity as useful [46]. This is a positive result, indicating a perceived recognised need and benefit in self-tracking technology. However, without qualitative data into the views of these older adults, it is hard to understand what value participants felt that the tracking technology held for them.

This perceived need amongst older adults for tracking physical activity is supported by a range of other studies. In a telephone survey of 1,013 older adults in Switzerland, Seifert et al., found that from 5 pre-selected reasons to track physical activity, the most common reasons were "'to track daily physical activity' (65.8\%), followed by 'to motivate myself to remain healthy' (58.9\%), [and] 'to exchange data on physical activity and health with friends' (21.5\%)" [67]. However, they also found that only $10 \%$ of respondents used a mobile health tracker, despite widespread technology use amongst their study population.

Through the use of a custom smartphone application, Steinert et al. investigated how adults over 60 with no smartphone experience engaged with technology-mediated tracking. Users could choose to monitor medication intake, nutrition, water intake, and physical or recreational activity. Participants were visited three times over the 4 week study. 21 of the 30 participants chose to focus at least in part on physical activity, again indicating a perceived need. However, the data collected through the study showed no significant change in the level of physical activity amongst those who were tracking it [68].

Moving beyond individual studies, Caldeira and Chen present an excellent review of the HCI and Medical Informatics literature on self-tracking amongst older adults [11]. Their findings correspond to the course we have noted through our literature review: that there is a wide range of studies that have established an interest amongst older adults in using technology to track health-related behaviour, but that there is much more mixed evidence regarding the efficacy of tracking technology [45]. Some studies find clear benefits and increased motivation to undertake physical activity (e.g. $[57,58,64])$ while other studies find no change in outcomes (e.g. [47, 72]).

Caldeira and Chen's review begins to unpick why there is a gap between the established perceived need for self-tracking technology for older adults, and the lack of efficacy and use amongst older adults. Partially this is a design issue, with a focus on designing for younger adults resulting 
in tools which are not appropriate, an argument also made by Seifert et al. [67]. The other identified shortcoming is the lack of an effective age-appropriate motivation strategy used within the technology, a consistent concern across much of the self-tracking technology (e.g. [1]).

\subsection{Motivation strategies and older adults}

Supporting motivation and encouraging behaviour change is complex, and the details of the various psychology theories are beyond the scope of this paper. Helpfully, Rodriguez et al. detail four of the most commonly used persuasion techniques used in tracking technology for older adults [60]:

(1) Abstraction. using "abstract representations based on metaphors to increase the users consciousness"

(2) Trigger the physical activity. "A trigger is defined as an alert that should be presented to users at a moment when they can perform the behavior"

(3) Historical information and reflection. Providing an "awareness of [their] past behavior as it relates to [their] goals"

(4) Positive and playful reinforcement. "If users perform the desired behavior, they should be rewarded; on the contrary, they should not receive rewards or information that makes them feel punished"

How these underlying techniques are implemented vary widely. Direito et al. analysed the top 40 smartphone apps aimed at modifying various health behaviours. Unsurprisingly, providing instruction, setting graded tasks and prompting self-monitoring were all heavily present. More surprisingly, planning social support/social change was a strategy used in just over half $(55 \%)$ of the analysed apps [14].

This is surprising as the majority of studies focus on the individual use of tracking technology, including all of the studies we've previously discussed.

Some researchers have noted that much of the research on activity-related personal informatics doesn't take into account the social network that is essential for the longer-terms success of the tracking technology [62]. Based on a 2-month study with 14 low-income families, Saksono et al. outline how the current practice of using activity trackers is designed to be an individual activity, with few families engaging in social discussions of the data. They conclude that one design direction is to rethink personal tracking as a family activity, using the data to promote collective reflection, leading to behaviour change.

The technology that does enable the social element of self-tracking tends to focus on a curated social network [28]. Through an intense iterative co-design process, Harrington et al. explored older adults views on health and fitness technologies, providing invaluable insight into shortcomings of existing approaches and directions of further exploration. As a result of this work they argue that this reliance on social networks is unattractive, and that supporting connection between older adults and familial groupings may be more advantageous.

Such a view is partially supported by the interviews completed by Rodriguez et al which found that active older adults tended to have a more extended network than less active older adults [60]. Research with longer-term users of tracking technology has highlighted the motivating value of being able to share your data with the right community and that this sense of connection can help support longer-term use of the technology [19].

However, focussing on familial groupings could lead designers to focus on a narrow interpretation of which members of a social network are significant. Given the literature on social factors and physical activity, exploring the potential for designing for an open community-based framing, where motivation comes from a sense of community connection is an underappreciated design direction. 


\subsection{Social factors and physical activity}

The impact of social networks on physical activity is well established within the health literature. While half of people who start exercise programmes will dropout within the first six months [15, 36], reviews of community-based group exercise for older adults have shown adherence rates of around $70 \%-75 \%[17,73]$.

Recognising the impact of community on adherence rates, there has been a rapid increase in social prescribing. Defined as "a means of enabling... primary care professionals to refer people to

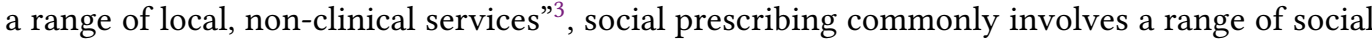
activities such as a range of sports, gardening or arts classes with the aim of improving mental health and physical well-being.

While social prescribing has increased, a systematic review of the literature published between 2000 and 2016, written in English, found 15 evaluations of social prescribing. These evaluations were mostly "small scale and limited by poor design and reporting", with the review concluding that "social prescribing is being widely advocated and implemented but current evidence fails to provide sufficient detail to judge either success or value for money" [5].

Clinical reports published in the BMJ also argue that while many studies indicate that there are benefits to patients, in terms of both mental wellbeing, physical health, and being socialised within the community, the current evidence base is somewhat limited [5].

Given the importance of social factors on supporting long-term engagement with physical activity, we argue that it is worth exploring how to combine the data-led approach of health tracking technologies with technology designed to support the development of community.

\subsection{Community Displays}

Whether it is a village noticeboard or a digital billboard in a large city, community displays serve the same purpose; to provide information to a community in a public location.

Much of the focus within the HCI community to community displays has been using them for gathering the community's opinion. In some cases this has focused on building-sized displays (e.g. [4]), others have focused on particular demographics, particularly younger people (e.g. [30]).

Taylor and their team have run multiple studies into community displays (e.g. [70, 71]). Focused on long-term deployments, their interest has been on whether these public displays have helped create a sense of community. Their conclusion has been that in the right circumstances, if designed correctly, community displays can be effective in changing behaviours and bringing communities together [70].

For example, the Tidy Street project $[6,38]$ had the goal of encouraging households to reduce their energy consumption through sharing data about the community's consumption. Graphs were chalked onto the road, comparing the resident's consumption against the average of the city. This public visualisation reduced electricity use by $15 \%$, as well as developing a sense of community.

There are a number of examples of community projects which have explored how emotions are captured, represented, and discussed in different social settings.

Mood Squeezer was designed as a stand-alone tangible installation that enabled office workers to reflect on their mood by squeezing one of a set of coloured stress balls placed in common walkways [20]. This data was visualised through lighting up a public floor. Based on 4-week field-trial, the authors argue that the public display helped promote individual and communal reflections about mood.

A similar approach is taken by Scolere et al. They designed a light-based sculpture that was displayed in the atrium of a University building. Users could select pictures that represent their

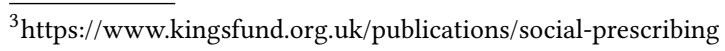


mood; these pictures then changed the colours of the sculpture. The authors argue that the public nature of the display led users to reflect on the connection between their own feelings, and the feelings of others [66].

Beyond building displays, the public display of mood has been used in designs ranging from emotion-based social media platforms [12] to clothing which changes colour based on mood [31].

The only project we are aware of that involves community based displays and addressing a health concern is the project from Parker et al. which explores technologies to address "diet-related health problems in low-income neighborhoods and amongst ethnic minority groups such as African Americans" [54].

Their project is based around a technology platform, Community Mosaic, which allows individuals to share their healthy eating ideas with one another as a means of advocating behavior change. Users can share nutrition-related photos and text messages through their mobile phones, with these message anonymized and aggregated before being visualised on an interactive public display.

Parker et al. report on a 12-week field study with 43 participants, with the public display installed within a branch of the YMCA [54]. Users shared 278 messages, and were viewed a total of 1585 times.

Reflecting on their work, Parker et al. propose an agenda for HCI research on health activism. Using an activist lens is highly contextualised, relating to a specific location, demographic, health system, political situation and economic system. However, their overarching recommendation that the field should be encouraging wellness through collective action aligns with our review of the literature.

The common thread across these studies of community displays is that the social dimension had benefits for the individuals involved. Given these experiences, we are interested in exploring whether community displays could be an interesting addition to the ecology of health tracking technology.

\subsection{Summary}

Having motivated the need for exploring the value of community displays to supporting the efficacy of health-tracking technology, we believe it is necessary to understand older adults' views on the design concept. In doing so, we develop a clear understanding of the key design characteristics that should underpin technology development and field deployment. We also build on the substantial literature we have discussed regarding the need to involve older adults in the design of tracking technology so that it fulfills their needs and desires.

It is thus important to consider the views of older adults on the concept of using public displays for supporting community-level health.

In answering this question through a series of workshops with older adults, we contribute an understanding of where the boundaries of acceptable use are, which will inform the development of difference forms of community displays using personal data.

\section{WORKSHOP DESIGN}

The purpose of the workshops was to explore older adults' views of community displays in the context of health and wellbeing.

Our study was designed in accordance with our University's code of ethics. We allowed participants the right to refuse to complete any of the activities, and we made it possible for participants to immediately end their participation if they so desired. None of the participants opted to do so. Consent was taken prior to the workshops beginning, alongside the collection of some basic demographic data. 


\subsection{Participants}

We ran four design workshops with 25 older adults across a medium-sized city in the UK. The town is socially and economically diverse. While we did not record individual information regarding participants socio-economic status, the workshops were conducted in neighborhoods which did differ in these respects. All of the workshops were conducted in pre-existing communities of older adults (three charity groups (Group-A, Group- $B$, Group- $C$ ) and a retirement community (Group-D)) Detailed demographics of our participants can be found in Table 1.

Group-B, Group-C and Group-D were all over 60; Group-A consisted of community workers focused on the needs of older adults (aged 35-54). The overall mean age was 63 (min 35, max 85, standard deviation of 14.7). Participants in Group-A were drawing on their extensive experience of working with older adults in order to discuss what they felt would be useful for the older adults they support.

19 participants identified as female, 6 as male, no one selected an alternative gender designation. The sessions were conducted in groups of between five and seven.

18 of the participants were aware of digital activity trackers (such as Fitbits) although only 6 currently used one.

8 participants felt like they exercised enough; 17 felt that they should exercise more. All but one of the participants undertook some form of exercise. The common means of exercise including walking (16), exercise classes (7), swimming (3), cycling (3), golf (2) and gardening (2).

\subsection{Procedure}

We employed a workshop approach, supported by a series of scenarios. Each of the workshops took place at the location the organisation normally meets. The workshops lasted between 45 and 97 minutes (mean $=69$ minutes). Each session was facilitated by two researchers. Our procedure was as follows:

(1) Study Introduction. Sessions began by the researcher explaining that the purpose of the study was to explore what physical activity trackers are and what community displays can look like. A short presentation was given to participants to provide some initial information. This presentation was followed by a round-table discussion of the participants' own experiences and feelings regarding activity tracking and community displays.

(2) Storyboard presentation and feedback. To scaffold discussion, five storyboard scenarios were developed which illustrated potential designs for health-related community displays. In developing these storyboards, the following design positions were represented:

- Individual data vs Communal data

- Collaborative vs Competitive

- Raw data vs Relative improvement

- Steps vs other measures of physical activity

- How long measuring over - today, week, month, year?

- Whether the system provides advice on physical activity or not

Figures 1 and 2 show representative examples of the storyboards, as we do not have space to include all five. Each of the storyboards situated and used the activity tracker in the context of an individual using the technology by themselves, but in the context of a broader community effort to increase physical activity. The scenarios used the abstraction, historical information and positive reinforcement persuasion techniques discussed previously [60].

We validated the scenarios with two pilot participants, refining our study procedure prior to running the workshops. 


\begin{tabular}{|c|c|c|c|c|c|c|c|}
\hline Group & Gender & Age & $\begin{array}{l}\text { Currently } \\
\text { use } \\
\text { tracking } \\
\text { technology }\end{array}$ & $\begin{array}{c}\text { Know } \\
\text { about } \\
\text { tracking } \\
\text { technology }\end{array}$ & $\begin{array}{c}\text { Do you } \\
\text { get } \\
\text { enough } \\
\text { exercise? }\end{array}$ & $\begin{array}{c}\text { Should } \\
\text { you be } \\
\text { more } \\
\text { active? }\end{array}$ & $\begin{array}{c}\text { Current } \\
\text { activities }\end{array}$ \\
\hline A & Female & 54 & $\mathrm{X}$ & $\checkmark$ & $\mathrm{X}$ & $\checkmark$ & $\begin{array}{l}\text { Cycling, } \\
\text { swimming }\end{array}$ \\
\hline A & Female & 35 & $\checkmark$ & $\checkmark$ & $\checkmark$ & $\checkmark$ & $\begin{array}{l}\text { Walking, } \\
\text { yoga }\end{array}$ \\
\hline A & Female & 46 & $\checkmark$ & $\checkmark$ & $\mathrm{X}$ & $\checkmark$ & Walking \\
\hline $\bar{A}$ & Female & 45 & $\mathrm{X}$ & $\mathrm{X}$ & $\mathrm{X}$ & $\checkmark$ & $\begin{array}{l}\text { Walking, } \\
\text { running }\end{array}$ \\
\hline A & Female & 40 & $\mathrm{X}$ & $\mathrm{X}$ & $\mathrm{X}$ & $\checkmark$ & none \\
\hline $\mathrm{A}$ & Female & 47 & $\bar{X}$ & $\checkmark$ & $\mathrm{X}$ & $\checkmark$ & Walking \\
\hline A & Female & 47 & $\mathrm{X}$ & $\checkmark$ & $\mathrm{X}$ & $\checkmark$ & Walking \\
\hline A & Female & 42 & $\mathrm{X}$ & $\checkmark$ & $\mathrm{X}$ & $\checkmark$ & Walking \\
\hline $\mathrm{B}$ & Female & 70 & $\bar{X}$ & $\bar{X}$ & $\bar{X}$ & $\checkmark$ & Gardening \\
\hline B & Female & 84 & $\mathrm{X}$ & $\mathrm{X}$ & $\checkmark$ & $\mathrm{X}$ & Gardening \\
\hline B & Female & 82 & $\mathrm{X}$ & $\mathrm{X}$ & $\mathrm{X}$ & $\checkmark$ & Walking \\
\hline B & Female & 85 & $\mathrm{X}$ & $\checkmark$ & $\mathrm{X}$ & $\checkmark$ & Walking \\
\hline B & Male & 67 & $\mathrm{X}$ & $\checkmark$ & $\checkmark$ & $\mathrm{X}$ & $\begin{array}{l}\text { Walking, } \\
\text { swimming }\end{array}$ \\
\hline $\mathrm{C}$ & Male & 67 & $\mathrm{X}$ & $\checkmark$ & $\checkmark$ & $\checkmark$ & Walking \\
\hline $\mathrm{C}$ & Female & 66 & Fitbit & $\checkmark$ & $\mathrm{X}$ & $\checkmark$ & Walking \\
\hline $\mathrm{C}$ & Female & 73 & $\mathrm{X}$ & $\checkmark$ & $\mathrm{X}$ & $\checkmark$ & $\begin{array}{c}\text { Keep } \\
\text { fit }\end{array}$ \\
\hline $\mathrm{C}$ & Male & 70 & $\checkmark$ & $\mathrm{X}$ & $\mathrm{X}$ & $\checkmark$ & $\begin{array}{l}\text { Walking, } \\
\text { cycling }\end{array}$ \\
\hline $\mathrm{C}$ & Female & 77 & $\mathrm{X}$ & $\checkmark$ & $\checkmark$ & $\checkmark$ & $\begin{array}{l}\text { Walking, } \\
\text { yoga }\end{array}$ \\
\hline $\mathrm{C}$ & Female & 68 & $\mathrm{X}$ & $\checkmark$ & $\checkmark$ & $\mathrm{X}$ & none \\
\hline $\mathrm{C}$ & Female & 66 & App & $\checkmark$ & $\mathrm{X}$ & $\checkmark$ & $\begin{array}{l}\text { Walking, } \\
\text { keep fit, } \\
\text { swimming }\end{array}$ \\
\hline $\mathrm{D}$ & Female & 69 & $\mathrm{X}$ & $\checkmark$ & $\mathrm{X}$ & $\checkmark$ & Walking \\
\hline $\mathrm{D}$ & Male & 68 & $\checkmark$ & $\checkmark$ & $\checkmark$ & $\mathrm{X}$ & $\begin{array}{l}\text { Cycling, } \\
\text { exercise } \\
\text { classes, } \\
\text { golf }\end{array}$ \\
\hline $\mathrm{D}$ & Female & 70 & $\mathrm{X}$ & $\checkmark$ & $\checkmark$ & $\mathrm{X}$ & $\begin{array}{l}\text { Gym, } \\
\text { exercise } \\
\text { classes, } \\
\text { golf }\end{array}$ \\
\hline $\mathrm{D}$ & Male & 83 & $\mathrm{X}$ & $\mathrm{X}$ & $\mathrm{X}$ & $\checkmark$ & Walking \\
\hline $\mathrm{D}$ & Male & 59 & $\mathrm{X}$ & $\checkmark$ & $\mathrm{X}$ & $\checkmark$ & Yoga \\
\hline
\end{tabular}

Table 1. Demographics of our participants. 
Throughout the presentation of the scenarios, the researchers facilitated a discussion over what elements of them the participants, liked, disliked (or had no views on), and what motivated those feelings.

(3) Storyboard creation. Having viewed all of the prepared storyboards, pairs of participants were asked to develop their own using blank templates, reflecting their personal preferences as to how they would like to see the community displays work. This was intended to be a communal activity for the group, encouraging further discussion through the creation process. Participants were not guided through the storyboard creation process, as we didn't want to influence the creativity or outcomes of the process. We believe that the previous discussions were sufficient to cause participants to reflect on their views, and develop their own storyboards. The storyboards were not reviewed with the focus group as a whole as we did not want to constrain participants to develop storyboards they were happy to share. Participants occassionally referred to their storyboards during the wrap-up discussion to illustrate a point they wanted to make.

While all of the pairs discussed the storyboards, not all of them completed the templates.

(4) Wrap-up discussion. To finish the workshop, the researchers facilitated a final round-table discussion, focussing on the two key questions:

- What are older adults' views on the concept of public displays for supporting community-level health?

- What information would older adults be willing to share/would like to receive through the community displays?
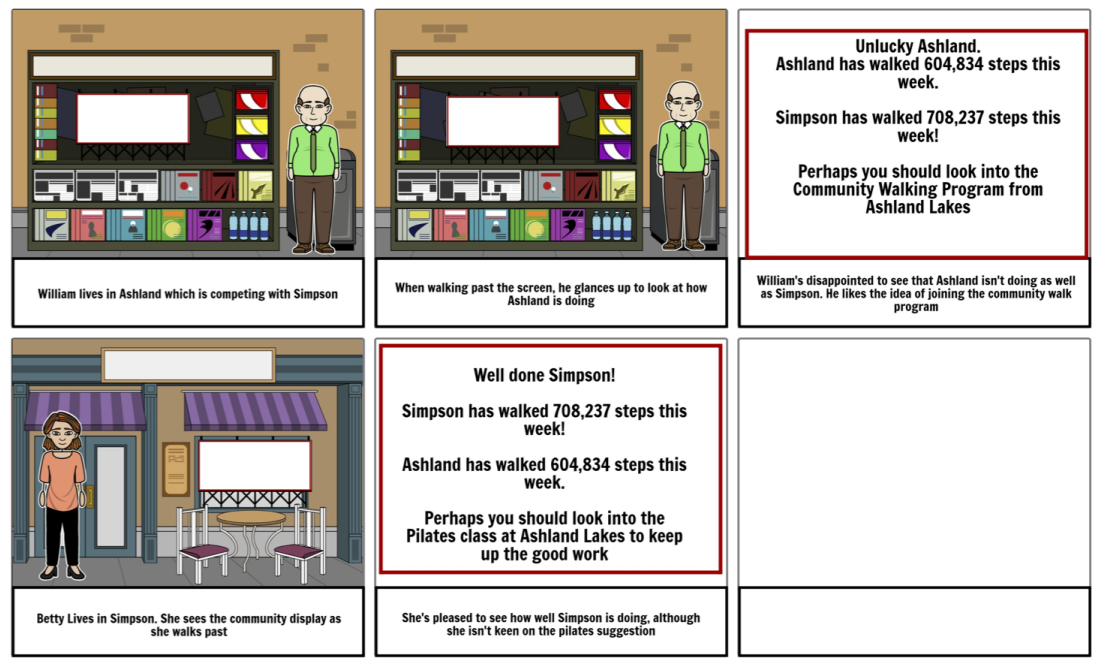

Fig. 1. A storyboard that focus on communal raw data about steps being presented in a competitive fashion.

\subsection{Analysis}

In analysing the data from the study, our main question was understanding the views of older adults on the concept of using public displays for supporting community-level health.

We collected two types of data to help answer this question. Firstly we audio recorded the workshops. Secondly, we had paper copies of the notes, sketches and storyboards the participants had developed. 

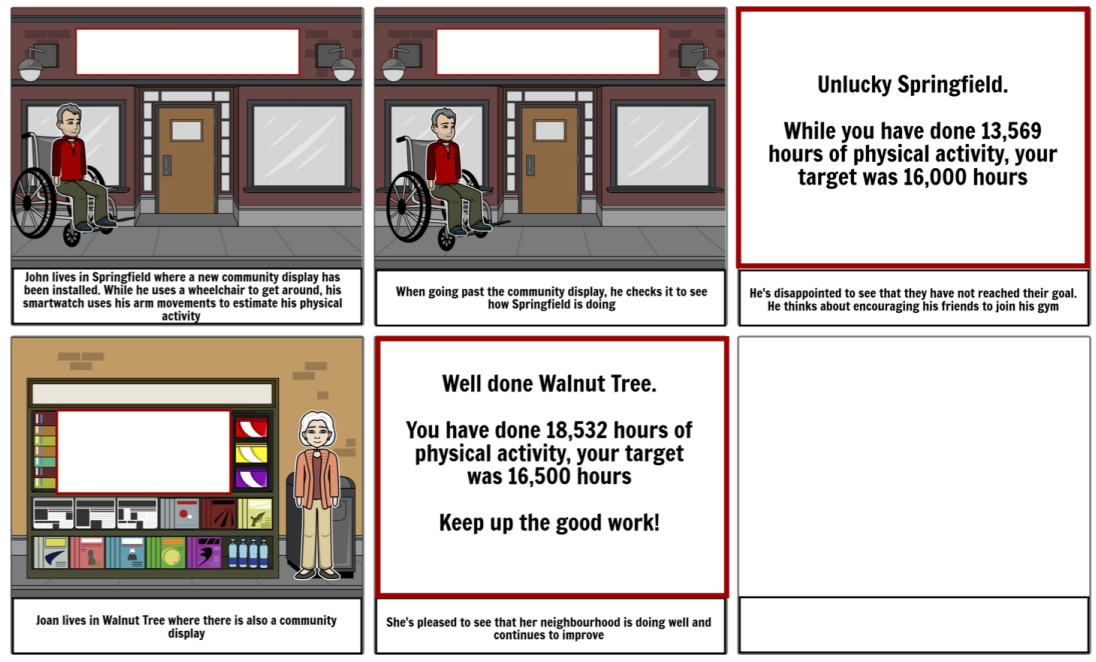

Fig. 2. A storyboard that focus on communal data about the number of hours of physical activity being presented in a collaborative fashion.

The audio recordings were our primary data source, as participants were encouraged to talkaloud during the storyboarding process. The recordings were transcribed, before being subjected to an inductive thematic analysis [9] in which we explored our participants' views. No codes or themes existed prior to the analysis; they were created through constant comparison of the data and the application of labels to the text. This process was tempered by our interest in our key question.

Having identified the themes from the audio recordings, we then applied these to the storyboards to ensure that they were an accurate and comprehensive reflection of what the participants had developed through the storyboards. No additional themes were generated through this process.

\section{RESULTS}

To contextualise our findings, we first note that our participants talked at length about the barriers they faced in getting physical activity, and their current practices regarding tracking their health.

The barriers our participants faced have been reported widely in the literature [65]. They included how age-related conditions and health limitations prevented them from undertaking as much physical activity as they would like, as well as a lack of confidence. The participants also discussed how difficulties in transportation were an issue in getting to locations suitable for exercise, whether that be an exercise class, or just somewhere pleasant to walk.

Only 6 of our participants currently tracked their physical activity. These participants discussed their practices within their workshops, leading to discussions familiar across the self-tracking literature. For some of these participants, it was very good at keeping them motivated, whereas others found that the technology was demotivating because of their repeated failure to hit the targets. Only two of the participants used the functionality to share some of their data privately with (family and friends). While these discussions are not novel, they are useful in contextualising the broader conversations that occurred within the workshops. 


\subsection{Response to the community display concept}

There was generally a positive response to the concept of community displays, with all but one participant seeing some value in the idea:

"That revolving thing... that's good for information. Because you might not think, 'Oh, there's a walking group going out on a Wednesday'... you know, dissemination of information is good" [Group-D]

Some participants noted that while the concept was a positive one, the design characteristics of the display (presented in the next section) would have a significant impact on whether people would respond positively to the displays. In particular, it was highlighted that saturation and irrelevance were significant risks to the success of such a display.

"As far as public display is concerned, I'm concerned about saturation. If you start lecturing people on every street corner, you're telling people to get fit, I think they'd cease to see it" [Group-B]

"if they were changed regularly enough and if they were relevant, so as [name] says, if they're telling a community about an event around fitness that's on, or a regular class or something, if they're giving that sort of information and it's changed frequently enough so that when people see the board that they pass every day it's different so they look at it, you know? I think that would be important" [Group-B]

The single participant who disliked the idea even in principle, thought that the community display was too invasive:

"It strikes me as big brother is watching" [Group-C]

This is related to a general resistance to linking personal data about physical activity to the display across all of the workshops, with the general view being that non-identifiable data was preferable for reasons of privacy:

"I think a lot of people wouldn't like individual data being put out there" [Group-B]"

These views are interesting, given that they start to address one aspect of our main question whether older adults see value in using public displays for supporting community-level health. Our data suggests broad consensus that such a technology could help support older adults undertake more physical activity, if designed appropriately. Such a consensus suggests that this is a promising direction of research, something the HCI community should note given the lack of health-related community technology we have previously noted [54]).

Given the identification of key design concerns even in discussing the broad acceptability of the notion of using community displays to support health, our participants also highlight the necessity of involving end-users in the design process (as discussed at length in our literature review). By sharing the views of communities more broadly, through papers such as this as well as other outputs, we gain a broader understanding across the $\mathrm{HCI}$ community as to the percieved value of certain design characteristics. As such, we now turn our attention to these specific design characteristics.

\subsection{Design characteristics of the community display}

Through the workshop discussions, and the development of scenario storyboards within the workshops, a variety of design characteristics were discussed.

4.2.1 Community level disempowerment. One of the main discussion points was about disempowerment, with all of the workshops expressing concern that any community initiative needs to 
consider the diversity of its members. This could be for a variety of reasons, whether financial, physical or emotional:

"I think it's got the potential for people to feel left out if they feel they feel, for whatever reason, emotionally or physically, they can't get involved with it. Although they probably could, but in their mind they think, 'Oh, well, look, they're doing all that. I can't do it."' [Group-A]

"And if you couldn't afford a Fitbit or anything like that, you would be excluded from taking part in the community bit, wouldn't you" [Group-B]

Some of the specific age-related concerns included mobility, physical ability and technological skill:

"But some areas have got a lot of people, older people where they're not as mobile. So, you're always going to get one that is better than the other" [Group-C]

"I went on the walking group and they buggered off and left us because we were too slow" [Group-D]

"But I find, as I get older, technology, it just bypasses me. I find it very difficult to pick things up now" [Group-D]

While the self-tracking community has moved towards a position of agreeing that older adults should be involved in the design process, the conversation has gone no further. There is a tendency, and the authors are as apt to do this as the broader community, to discuss older adults as a category group, not necessarily reflecting on the many varied and broad variations in opinions and abilities amongst such a crude categorisation [43]. Research has shown that technological health interventions tend to disproportionately benefit the advantaged [74].

Our data drives this home, and highlights that our participants, and older adults more generally, are not by any means a homogenous group. Designing for them as a singular group will always be disenfranchising and limiting, a point we return to in our discussion.

4.2.2 Nature of the messaging. Part of the solution to disempowerment is to ensure that the messaging of any community display is inclusive. There was wide agreement across all of the workshops that the messaging must be positive and reinforcing, rather than negative and critical:

'I don't like the negative bit, 'Oh, unlucky. Oh, bad luck.' I think what you could have is,

'Well done, well done. Your target was,' in tiny little writing. Then they can see that they didn't reach it." [Group-A]

"It's got to be worded really carefully so it doesn't come across as criticism. 'This week, you've failed."' [Group-B]

Our participants reiterated the importance of providing context to whatever data was displayed. Beyond questions as to the accuracy and meaningfulness of the data (as noted earlier, participants were aware of the shortcomings of step-count data), our participants were clear that putting the data into a context that was meaningful would be more motivating. Distance or time were highlighted as more relevant to lived experience than, for example, the number of steps:

"'You've walked the equivalent of Oxford to London in the last month,' or something, little things that put it into perspective and things." [Group-A]

One workshop took this a step further, and discussed whether highlighting particular case studies to demonstrate reality could be particularly powerful:

"It could be 'Fohn saw the yoga session advertised and started to go, made new friends, said it made him feel happy.' I don't know, something like that. They thought it might be quite a nice way to motivate people to think, 'Oh actually, maybe I'll give that a try,' in 
that way, rather than using it just about steps and data. It could be more about a bit more real-life examples of what people have done to get more active." [Group-A]

This was compared against the advertising strategy for many fitness organisations which promote a certain body ideal. Given that this is not feasible for the majority of people, such advertising can be extremely demotivating, particularly for older adults who are rarely shown in a realistic fashion:

"even just the posters and that, because when we went over to [name] Leisure Centre they had pictures of buff guys and really skinny, tiny women. That really puts you off, but in reality (Laughter)... It's the advertising. Why would you want to go and join that when you think all these people on these posters are the ones that go?" [Group-A]

Our data highlights that the messaging through the imagined community display must be positive and reinforcing, ensuring that such a system would be inclusive to as broad a cross-section of the community as possible.

4.2.3 Local community information. Each of the workshops discussed the importance of keeping the information on the displays extremely local. Whereas information about local options for exercise could have previously been provided by a local newspaper, the move to social media has made it harder for some people to access local information, particularly if they do not belong to social media.

[P1] "No local paper so hard to know what is going on"

[P2] "If you're not on social media, you haven't got a clue what's going on, have you" [Group-C]

Therefore, making the information available through a local display would empower the local community to have more control over the sharing of local information, particularly for small community groups who may struggle to otherwise advertise:

"To publicise those sorts of groups to local communities, I think, would be one of the things that your digital displays would really be effective at doing" [Group-B]

The physical nature of the display also determines that the audience remains local, or at least has a local connection, which was seen to be a positive aspect:

"But through [name] village, it would be nice to have a board, that you drive into [name] village - not to take your eye off the road or that - or people who are walking around, and say events that are on this week. You know, if you're having a coffee morning or you're having a gardening do... what kinds of activities there are locally, what time they start" [Group-D]

"As long as it was local so that they could physically walk to - if they're walking past the sign they might go, 'Right, actually I'll go to that now,' or something... it would need to be very local and very local information. It'd be irrelevant if you were in [area] and you were told something over in [area] or something" [Group-A]

By preserving this link to the local area, there was also some discussion as to whether the displays could act as a mechanism for connecting people together, so that people could join new groups together rather than having to be motivated and brave enough to try something new on their own:

"And, you know, 'If you don't want to go on your own, come with me,' because, actually we haven't written that, but I think that's also very important for starting any sort of exercise is if somebody says, 'Well, I do it. Come with me."' [Group-B]

Such results correspond with a range of community initiatives, which tend to highlight the importance of locality in forming strong community bonds [54]. As one of the first studies into the 
use of community displays linked with health tracking technology, this result may not be novel, but it reaffirms the value of locality when developing initiatives in this context.

4.2.4 Collaboration vs competition. Of the design parameters explored through the storyboards, the only factor that led to significant discussion was whether the displays should include elements of competition or collaboration.

The overwhelming view was that competition between areas would be a poor decision. One reason would be the difficulty of pairing neighbourhoods of similar demographics:

"The only thing I didn't like was the competition between different - it's just because I didn't think that that would actually be fair" [Group-A]

With a second reason being that while competitiveness could be motivating for some individuals, it could be demotivating for some individuals and it is hard to strike a balance when working across a community:

\section{"It wouldn't appeal to me" [Group-D]}

"I think it's quite personal. Some people I know are just absolutely inspired by that sense of competition, and other people are a bit crushed by it... How do you measure that across a community?" [Group-B]

A final reason was noted that some areas already have issues with one another, and that a competition between them could further stoke tensions:

"You would not want to display [area] data next to [area] data. There are enough dynamics between those two communities anyway" [Group-B]

In contrast, building collaborative elements into the display were seen as hugely positive in all of the workshops:

"It could help people come together and exercise more." [Group-A]

"I think when you've got a group you encourage each other, because you'd all be comparing

- 'What did you do this week?"' [Group-D]

Further emphasising the importance of community and locality that were discussed in the previous section.

Being part of a community involves some sense of belonging to a grouping beyond the individual [32]. One interpretation of this is that belonging to a community is partially defined by whom is excluded from that community, who lives outside of the accepted norms of that community [69]. In this sense, it follows for the community displays to focus on collaboration rather than competition; that the technology acts as an additional bond that brings a community together, regardless of what any other community is doing. Early research into exercise programs using workplace competition highlighted that smaller organisations tended to have a greater rate of participation, in part due to an increased pressure to belong to the community [7].

While collaboration appears to be the preference amongst our participants, there are risks with such a design approach. For example, the community displays could help create cliques within the co-located community, developing a division between those who use the system and those that do not.

Given the complexity of intra-community dynamics, ensuring that the technology is supporting rather than disintegrating a local community is of sufficient challenge to designers, without becoming overwhelmed by the potential risks of technology disrupting delicate inter-community relationships. 


\section{DISCUSSION}

Our participants had a generally positive response to the concept of community displays, indicating that such displays might motivate them to undertake additional physical activity. However, through these discussions it is abundantly clear that the design of such displays is not trivial, and that small changes to the design could have an immense impact on their efficacy. We therefore start our discussion by exploring three of the key design principles expressed across the focus groups.

\subsection{Design Characteristics}

The three design characteristics identified by our work are the need for designs to be inclusive, the benefits of collaboration over competitiveness and the advantages of focussing on local concerns. In each subsection, we first discuss the implications for designing health-related community displays, before considering the broader implications of these design characteristics.

5.1.1 Inclusivity. One of the strongest themes running throughout our focus groups was the importance of inclusivity, that anybody could benefit from the displays. In Section 4.2.1, we highlighted that one of the main discussion points of the focus groups was about disempowerment, with all of the workshops expressing concern that any community initiative needs to consider the diversity of its members. This included physical aspects of an individual's health, their financial situation, their technological skill level or emotional aspects of their health.

This is a clear statement of inclusive design [50], where the principle is clear: give appropriate consideration to all potential users of a technology during early stages of the design. Proponents argue that inclusive design improves the functionality and aesthetics of systems for everybody.

The authors come from more of a user-centered design tradition where focussing the demographic of the target population allows for a more appropriate response. While this leads to issues in terms of defining who can participate [35, 76], such concerns are amplified if we are trying to design for all potential users.

Not only does this inclusivity impact the data being recorded (i.e. what the proxy measures of physical activity are) but also the nature of the messaging communicated through the displays. As other digital civics projects have noted, the public narrative of a digital civics project is key [22]. Our research highlights that positive reinforcement, coupled with a meaningful contextualisation of the collected data would be the most suitable design direction.

Beyond these recommendations over the design of the community display technology, the importance of inclusivity is as relevant to the way in which such technologies are developed.

While the self-tracking community is moving towards a position of agreeing that older adults should be involved in the design process, the conversation has gone no further. There is a tendency, and the authors are as apt to do this as the broader community, to discuss older adults as a category group, not necessarily reflecting on the many varied and broad variations in opinions, abilities, financial resource that individuals may have. There is also little consideration of how other needs such as disabilities, racial disparities or socioeconomic unfairness - create competing pressures, which can lead to tokenism [41]. Taking an activist approach to dealing with these issues in the context of technological-mediated health can be beneficial [54], but risks tightly scoping the nature of who is being advocated for.

We thus see an ongoing research direction for the CSCW community in terms of understanding how to aim for more inclusive design, and how to deal with the potential conflicts between the conflicts of different groups.

In putting together engagement approaches, there is no panacea to this, as ensuring universality is an admirable, if ultimately unachievable aim. However, certain concrete measures can be taken, particularly in terms of being imaginative about providing options for varied participation and 
in how recruitment is achieved. As we cannot compel people to participate, having diversity and inclusion and the forefront, and valuing it as much as participation at all, has to be the starting point for a designer. We also have to acknowledge that exclusion can always occur, despite specific attempts to ensure inclusion [69].

One way for the CSCW community to encourage inclusivity is to be clearer in the expectations regarding reporting the characteristics of study populations, for example including the "race/ethnicity/culture/language, occupation, gender/sex, religion, education, SES, and social capital as well as age, disability, and sexual orientation" [74]. While this transparency could prove helpful in contextualising results, compelling it could lead to a disinclination of participation due to participants not wanting to disclose so much sensitive data before participation.

5.1.2 Collaboration. The majority of physical activity tracking systems contain elements of competition, whether this is with yourself (as per the Fitbit daily goals) or with your social network (as per Strava).

Our participants argued that expanding this competitiveness to a community-scale would be extremely demotivating for some, particularly those who struggle with physical activity who might benefit the most from the community displays. Instead our focus groups argued for a privacy-aware contextual service $[40,49]$ which could bring all elements of the community together, rather than rank and compare individuals.

Previous work in digital civics has highlighted the importance of forming personal connections and social networks beyond any technical implementation [16, 23, 27, 33]. Our research has shown the same thing in the context of community displays; the motivating factor comes from sharing the data and creating a sense of a community, rather than achieving set goals. In doing so, we move away from extrinsic rewards towards longer-term intrinsic motivation [61].

Based on our results, we thus argue that the current competition focus of many physical activity trackers is a limitation, and the CSCW community should further explore the benefits of more collaborative designs.

More broadly, this recommendation is supported by work which suggests that competition and gamification is most effective in the short-term [39], whereas building a collaborative community necessitates a much long-term approach. This has implications for our community in terms of how we approach researching technologically-mediated health interventions, particularly in terms of what success looks like. In addition to the easier-to-measure short-term interventions which currently dominate, we need to better incentivise studies that operate over the long-term.

5.1.3 Local concerns. In 1985, Neil Postman's book carefully detailed how our changing media landscape has gradually reduced the importance of local news as we become immersed within a wider media landscape [56]. Undoubtedly since then the Internet has accelerated this change so that we now live and work within a 'global village'.

There are elements of our lives where this focus beyond the locality doesn't work well. Our focus groups strongly argued that the community displays should be inherently based around a physical community, and provide access to news about the local community, local activity classes and consolidate the physical activity tracking data for only that community.

Such a position has been found in other digital civics work [22]. The hyperbole around many digital initiatives - with Smart Cities being the latest in a long line - forgets that at heart, 'all politics is local'. People live, work and enjoy leisure within the local community. We argue that as physical activity tracking moves from an individual activity to more of a social activity, we should focus on ensuring that the link to local communities remains strong.

In doing so, we join an increasing trend within the CSCW community encouraging research to go against the trend to develop technologies that aspire to be global [44, 63], but to reaffirm the 
importance of small scale localities in enabling the collective pursuit of change in the context of health through community action $[25,54]$.

\subsection{Empowerment and Control}

User-centered design researchers have to contend with the complexity of power distribution and decision making in UCD projects [8,59]. Fundamentally these design methods have "the ambition that users should take part in all types of decisions - also in the big decisions, like defining the problem and its solution - and be given a voice, as well as the power to participate in the decision-making" [8, p. 41]

Two of our focus groups had long discussions regarding the suitability of community technology being designed by individuals not within the demographic, whether this was for age reasons [Group-C] or in terms of being situated within the physical neighborhood [Group-D]. While both focus groups recognised that we were trying to gain an understanding of their lived experience, and design technology that supported their aims and objectives in a suitable manner, both groups argued that we could not have a deep understanding of their concerns or needs. Without this deep understanding of their lived experience, they expressed deep reservations about us being able to design responsibly.

These concerns have been recognised by others working in the area of digital civics. The selection of participants for research projects is always a political matter, which can privilege those social groups who can more easily contribute and already have relevant competencies and values [75]. In our design practices, we are trained to be mindful of who is involved, with what roles and power [21].

This issue however goes deeper than this, and suggests that our role as research partners would still be insufficient to deal with issues around empowerment. This is as an ongoing challenge which is particularly pertinent when operating in communities in the context of health and wellbeing.

Key to addressing this challenge is the sustainability of the envisaged technology, in both financial and technical terms. Various digital civics projects have attempted to upskill communities to ensure interventions continue beyond (e.g. $[22,23]$ ) but financial sustainability remains much more challenging. In sustaining interventions, it is more viable to empower communities and transfer control as compared to time-boxed research projects.

Planning for sustainability has to be valued from the start of an intervention, but more importantly valued by both the research community and funders. The research community should be creating incentives in terms of expecting sustainability to form part of any publication, as well as costing the time and resources needed for sustainability in research grants. Without such changes, while we may be inclusive and support empowered design processes, the long-term success of our interventions will always be limited by the resources of the related research project, making true empowerment of communities impossible.

\section{CONCLUSION}

In this paper we have described a design exploration into the suitability of using community displays to support older adults to increase their level of physical activity. We highlight that three design principles - inclusivity, collaboration and locality - are key elements in the design of any community displays. We expand beyond these design principles to discuss the implications of our work for the broader CSCW community.

This study provides foundational support for further exploration of community displays to support older adults increase physical activity, validating the concept. In future work we plan on exploring whether implementations of such systems can collect meaningful data in the long-term 
across a community and explore whether such devices can actually increase the physical activity of older adults.

\section{ACKNOWLEDGMENTS}

The authors would like to thank everybody in Milton Keynes who has taken part in any of our engagement activities. This work was completed with support from BBSRC grant BB/T018194/1 and EPSRC grant EP/P01013X/1.

\section{REFERENCES}

[1] Schlomann A. 2017. A case study on older adults' long-term use of an activity tracker. Gerontechnology 16 (2017), 114-125. https://doi.org/10.4017/gt.2017.16.2.007.00

[2] Maliha Agha and Riaz Agha. 2017. The rising prevalence of obesity, part A, impact on public health. International journal of surgery. Oncology 2, 7 (2017), e17. https://doi.org/10.1097/IJ9.0000000000000017

[3] Nabil Alshurafa, Jayalakshmi Jain, Rawan Alharbi, Gleb Iakovlev, Bonnie Spring, and Angela Pfammatter. 2018. Is More Always Better? Discovering Incentivized MHealth Intervention Engagement Related to Health Behavior Trends. Proc. ACM Interact. Mob. Wearable Ubiquitous Technol. 2, 4, Article 153 (Dec. 2018), 26 pages. https://doi.org/10.1145/3287031

[4] Moritz Behrens, Nina Valkanova, Ava Fatah gen. Schieck, and Duncan P. Brumby. 2014. Smart Citizen Sentiment Dashboard: A Case Study Into Media Architectural Interfaces. In Proceedings of The International Symposium on Pervasive Displays (Copenhagen, Denmark) (PerDis '14). Association for Computing Machinery, New York, NY, USA, 19-24. https://doi.org/10.1145/2611009.2611036

[5] Liz Bickerdike, Alison Booth, Paul M Wilson, Kate Farley, and Kath Wright. 2017. Social prescribing: less rhetoric and more reality. A systematic review of the evidence. BMJ Open 7, 4 (2017), e013384. https://doi.org/10.1136/bmjopen2016-013384 arXiv:https://bmjopen.bmj.com/content/7/4/e013384.full.pdf

[6] Jon Bird and Yvonne Rogers. 2010. The pulse of tidy street: Measuring and publicly displaying domestic electricity consumption.

[7] Susan M. Blake, Carl J. Caspersen, John Finnegan, Richard A. Crow, Maurice B. Mittlemark, and Kevin R. Ringhofer. 1996. The Shape up Challenge: A Community-Based Worksite Exercise Competition. American fournal of Health Promotion 11, 1 (1996), 23-34. https://doi.org/10.4278/0890-1171-11.1.23

[8] Tone Bratteteig and Ina Wagner. 2012. Disentangling Power and Decision-Making in Participatory Design. In Proceedings of the 12th Participatory Design Conference: Research Papers - Volume 1 (Roskilde, Denmark) (PDC '12) Association for Computing Machinery, New York, NY, USA, 41-50. https://doi.org/10.1145/2347635.2347642

[9] Virginia Braun and Victoria Clarke. 2006. Using thematic analysis in psychology. Qualitative Research in Psychology 3 , 2 (2006), 77-101.

[10] Clara Caldeira, Matthew Bietz, and Yunan Chen. 2016. Looking for the Unusual: How Older Adults Utilize SelfTracking Techniques for Health Management. In Proceedings of the 10th EAI International Conference on Pervasive Computing Technologies for Healthcare (Cancun, Mexico) (PervasiveHealth '16). ICST (Institute for Computer Sciences, Social-Informatics and Telecommunications Engineering), Brussels, BEL, 227-230.

[11] Clara Caldeira and Yunan Chen. 2019. Seniors and Self-tracking Technology. Springer International Publishing, Cham, 67-79. https://doi.org/10.1007/978-3-030-06076-3_5

[12] Karen Church, Eve Hoggan, and Nuria Oliver. 2010. A Study of Mobile Mood Awareness and Communication through MobiMood. In Proceedings of the 6th Nordic Conference on Human-Computer Interaction: Extending Boundaries (Reykjavik, Iceland) (NordiCHI '10). Association for Computing Machinery, New York, NY, USA, 128-137. https: //doi.org/10.1145/1868914.1868933

[13] Sofie Compernolle, Corneel Vandelanotte, Greet Cardon, Ilse De Bourdeaudhuij, and Katrien De Cocker. 2015. Effectiveness of a Web-Based, Computer-Tailored, Pedometer-Based Physical Activity Intervention for Adults: A Cluster Randomized Controlled Trial. J Med Internet Res 17, 2 (09 Feb 2015), e38. https://doi.org/10.2196/jmir.3402

[14] Artur Direito, Leila Pfaeffli Dale, Emma Shields, Rosie Dobson, Robyn Whittaker, and Ralph Maddison. 2014. Do physical activity and dietary smartphone applications incorporate evidence-based behaviour change techniques? BMC Public Health 14, 646 (2014).

[15] Rod K. Dishman. 2001. The Problem of Exercise Adherence: Fighting Sloth in Nations With Market Economies. Quest 53, 3 (2001), 279-294. https://doi.org/10.1080/00336297.2001.10491745

[16] Shelly Farnham, David Keyes, Vicky Yuki, and Chris Tugwell. 2012. Puget Sound off: Fostering Youth Civic Engagement through Citizen Journalism. In Proceedings of the ACM 2012 Conference on Computer Supported Cooperative Work (Seattle, Washington, USA) (CSCW '12). Association for Computing Machinery, New York, NY, USA, 285-294. https: //doi.org/10.1145/2145204.2145251

Proc. ACM Hum.-Comput. Interact., Vol. 5, No. CSCW1, Article 85. Publication date: April 2021. 
[17] Clare Farrance, Fotini Tsofliou, and Carol Clark. 2016. Adherence to community based group exercise interventions for older people: A mixed-methods systematic review. Preventive Medicine 87 (2016), 155 - 166. https://doi.org/10. 1016/j.ypmed.2016.02.037

[18] Duggan M Fox S. 2013. Tracking for health. Pew Research Center’s Internet and American Life Project.

[19] Thomas Fritz, Elaine M. Huang, Gail C. Murphy, and Thomas Zimmermann. 2014. Persuasive Technology in the Real World: A Study of Long-Term Use of Activity Sensing Devices for Fitness. In Proceedings of the SIGCHI Conference on Human Factors in Computing Systems (Toronto, Ontario, Canada) (CHI '14). Association for Computing Machinery, New York, NY, USA, 487-496. https://doi.org/10.1145/2556288.2557383

[20] Sarah Gallacher, Jenny O’Connor, Jon Bird, Yvonne Rogers, Licia Capra, Daniel Harrison, and Paul Marshall. 2015 Mood Squeezer: Lightening up the Workplace through Playful and Lightweight Interactions. In Proceedings of the 18th ACM Conference on Computer Supported Cooperative Work and Social Computing (Vancouver, BC, Canada) (CSCW '15). Association for Computing Machinery, New York, NY, USA, 891-902. https://doi.org/10.1145/2675133.2675170

[21] Katarina L. Gidlund. 2012. Designing for All and No One - Practitioners Understandings of Citizen Driven Development of Public e-Services. In Proceedings of the 12th Participatory Design Conference: Research Papers - Volume 1 (Roskilde, Denmark) (PDC '12). Association for Computing Machinery, New York, NY, USA, 11-19. https://doi.org/10.1145/ 2347635.2347638

[22] Daniel Gooch, Matthew Barker, Lorraine Hudson, Ryan Kelly, Gerd Kortuem, Janet Van Der Linden, Marian Petre, Rebecca Brown, Anna Klis-Davies, Hannah Forbes, Jessica Mackinnon, Robbie Macpherson, and Clare Walton. 2018. Amplifying Quiet Voices: Challenges and Opportunities for Participatory Design at an Urban Scale. ACM Trans. Comput.-Hum. Interact. 25, 1, Article 2 (Jan. 2018), 34 pages. https://doi.org/10.1145/3139398

[23] Daniel Gooch, Ryan M. Kelly, Alexandra Stiver, Janet [van der Linden], Marian Petre, Mike Richards, Anna Klis-Davies, Jessica MacKinnon, Robbie Macpherson, and Clare Walton. 2020. The benefits and challenges of using crowdfunding to facilitate community-led projects in the context of digital civics. International fournal of Human-Computer Studies 134 (2020), 33 - 43. https://doi.org/10.1016/j.ijhcs.2019.10.005

[24] Rúben Gouveia, Evangelos Karapanos, and Marc Hassenzahl. 2018. Activity Tracking in Vivo. In Proceedings of the 2018 CHI Conference on Human Factors in Computing Systems (Montreal QC, Canada) (CHI '18). Association for Computing Machinery, New York, NY, USA, Article 362, 13 pages. https://doi.org/10.1145/3173574.3173936

[25] Andrea Grimes, Martin Bednar, Jay David Bolter, and Rebecca E. Grinter. 2008. EatWell: Sharing Nutrition-Related Memories in a Low-Income Community. In Proceedings of the 2008 ACM Conference on Computer Supported Cooperative Work (San Diego, CA, USA) (CSCW '08). Association for Computing Machinery, New York, NY, USA, 87-96. https: //doi.org/10.1145/1460563.1460579

[26] Rebecca Gulotta, Jodi Forlizzi, Rayoung Yang, and Mark Wah Newman. 2016. Fostering Engagement with Personal Informatics Systems. In Proceedings of the 2016 ACM Conference on Designing Interactive Systems (Brisbane, QLD, Australia) (DIS '16). Association for Computing Machinery, New York, NY, USA, 286-300. https://doi.org/10.1145/ 2901790.2901803

[27] Derek L. Hansen, Jes A. Koepfler, Paul T. Jaeger, John C. Bertot, and Tracy Viselli. 2014. Civic Action Brokering Platforms: Facilitating Local Engagement with ACTion Alexandria. In Proceedings of the 17th ACM Conference on Computer Supported Cooperative Work and Social Computing (Baltimore, Maryland, USA) (CSCW'14). Association for Computing Machinery, New York, NY, USA, 1308-1322. https://doi.org/10.1145/2531602.2531714

[28] Christina N. Harrington, Lauren Wilcox, Kay Connelly, Wendy Rogers, and Jon Sanford. 2018. Designing Health and Fitness Apps with Older Adults: Examining the Value of Experience-Based Co-Design. In Proceedings of the 12th EAI International Conference on Pervasive Computing Technologies for Healthcare (New York, NY, USA) (PervasiveHealth '18). Association for Computing Machinery, New York, NY, USA, 15-24. https://doi.org/10.1145/3240925.3240929

[29] Louise C. Hawkley, Ronald A. Thisted, and John T. Cacioppo. 2009. Loneliness predicts reduced physical activity: cross-sectional and longitudinal analyses. Health Psychology 28 (2009), 354 - 363. https://doi.org/10.1037/a0014400

[30] Simo Hosio, Vassilis Kostakos, Hannu Kukka, Marko Jurmu, Jukka Riekki, and Timo Ojala. 2012. From School Food to Skate Parks in a Few Clicks: Using Public Displays to Bootstrap Civic Engagement of the Young. In Pervasive Computing, Judy Kay, Paul Lukowicz, Hideyuki Tokuda, Patrick Olivier, and Antonio Krüger (Eds.). Springer Berlin Heidelberg, Berlin, Heidelberg, 425-442.

[31] Noura Howell, Laura Devendorf, Rundong (Kevin) Tian, Tomás Vega Galvez, Nan-Wei Gong, Ivan Poupyrev, Eric Paulos, and Kimiko Ryokai. 2016. Biosignals as Social Cues: Ambiguity and Emotional Interpretation in Social Displays of Skin Conductance. In Proceedings of the 2016 ACM Conference on Designing Interactive Systems (Brisbane, QLD, Australia) (DIS '16). Association for Computing Machinery, New York, NY, USA, 865-870. https://doi.org/10.1145/2901790.2901850

[32] Joseph Hughey and Paul W. Speer. 2002. Community, Sense of Community, and Networks. Springer US, Boston, MA, 69-84. https://doi.org/10.1007/978-1-4615-0719-2_4 
[33] Julie S. Hui, Michael D. Greenberg, and Elizabeth M. Gerber. 2014. Understanding the Role of Community in Crowdfunding Work. In Proceedings of the 17th ACM Conference on Computer Supported Cooperative Work and Social Computing (Baltimore, Maryland, USA) (CSCW'14). Association for Computing Machinery, New York, NY, USA, 62-74. https://doi.org/10.1145/2531602.2531715

[34] Sarah E. Jackson, Rebecca J. Beeken, and Jane Wardle. 2015. Obesity, perceived weight discrimination, and psychological well-being in older adults in England. Obesity 23, 5 (2015), 1105-1111. https://doi.org/10.1002/oby.21052 arXiv:https://onlinelibrary.wiley.com/doi/pdf/10.1002/oby.21052

[35] Andrea Kavanaugh, John M. Carroll, Mary Beth Rosson, Debbie D. Reese, and Than T. Zin. 2004. Participating in civil society: the case of networked communities. Interacting with Computers 17, 1 (11 2004), 9-33. https: //doi.org/10.1016/j.intcom.2004.10.006 arXiv:https://academic.oup.com/iwc/article-pdf/17/1/9/2289037/iwc17-0009.pdf

[36] "Clare Killingback, Fotini Tsofliou, and Carol Clark". 2017. Older people's adherence to community-based group exercise programmes: a multiple-case study. BMC Public Health 17, 115 (2017). https://doi.org/10.1186/s12889-017-4049-6

[37] Predrag Klasnja, Sunny Consolvo, and Wanda Pratt. 2011. How to Evaluate Technologies for Health Behavior Change in HCI Research. In Proceedings of the SIGCHI Conference on Human Factors in Computing Systems (Vancouver, BC, Canada) (CHI '11). Association for Computing Machinery, New York, NY, USA, 3063-3072. https://doi.org/10.1145/ 1978942.1979396

[38] Lisa Koeman, Vaiva Kalnikaitundefined, Yvonne Rogers, and Jon Bird. 2014. What Chalk and Tape Can Tell Us: Lessons Learnt for Next Generation Urban Displays. In Proceedings of The International Symposium on Pervasive Displays (Copenhagen, Denmark) (PerDis '14). Association for Computing Machinery, New York, NY, USA, 130-135 https://doi.org/10.1145/2611009.2611018

[39] Jonna Koivisto and Juho Hamari. 2014. Demographic differences in perceived benefits from gamification. Computers in Human Behavior 35 (2014), 179 - 188. https://doi.org/10.1016/j.chb.2014.03.007

[40] Hyosun Kwon, Joel E. Fischer, Martin Flintham, and James Colley. 2018. The Connected Shower: Studying Intimate Data in Everyday Life. Proc. ACM Interact. Mob. Wearable Ubiquitous Technol. 2, 4, Article 176 (Dec. 2018), 22 pages. https://doi.org/10.1145/3287054

[41] Amanda Lazar and Emma E. Dixon. 2019. Safe Enough to Share: Setting the Dementia Agenda Online. Proc. ACM Hum.-Comput. Interact. 3, CSCW, Article 85 (Nov. 2019), 23 pages. https://doi.org/10.1145/3359187

[42] Brian Y. Lim, Judy Kay, and Weilong Liu. 2019. How Does a Nation Walk? Interpreting Large-Scale Step Count Activity with Weekly Streak Patterns. Proc. ACM Interact. Mob. Wearable Ubiquitous Technol. 3, 2, Article 57 (June 2019), 46 pages. https://doi.org/10.1145/3328928

[43] Stephen Lindsay, Daniel Jackson, Guy Schofield, and Patrick Olivier. 2012. Engaging Older People Using Participatory Design. In Proceedings of the SIGCHI Conference on Human Factors in Computing Systems (Austin, Texas, USA) (CHI '12). Association for Computing Machinery, New York, NY, USA, 1199-1208. https://doi.org/10.1145/2207676.2208570

[44] Diane Maloney-Krichmar and Jenny Preece. 2005. A Multilevel Analysis of Sociability, Usability, and Community Dynamics in an Online Health Community. ACM Trans. Comput.-Hum. Interact. 12, 2 (June 2005), 201-232. https: //doi.org/10.1145/1067860.1067864

[45] Siobhan K McMahon, Beth Lewis, Michael Oakes, Weihua Guan, Jean F Wyman, and Alexander J Rothman. 2016. Older Adults' Experiences Using a Commercially Available Monitor to Self-Track Their Physical Activity. 7MIR mHealth uHealth 4, 2 (13 Apr 2016), e35. https://doi.org/10.2196/mhealth.5120

[46] Siobhan K McMahon, Beth Lewis, Michael Oakes, Weihua Guan, Jean F Wyman, and Alexander J Rothman. 2016. Older Adults' Experiences Using a Commercially Available Monitor to Self-Track Their Physical Activity. 7MIR mHealth uHealth 4, 2 (13 Apr 2016), e35. https://doi.org/10.2196/mhealth.5120

[47] Marion E. T. McMurdo, Jacqui Sugden, Ishbel Argo, Paul Boyle, Derek W. Johnston, Falko F. Sniehotta, and Peter T. Donnan. 2010. Do Pedometers Increase Physical Activity in Sedentary Older Women? A Randomized Controlled Trial fournal of the American Geriatrics Society 58, 11 (2010), 2099-2106. https://doi.org/10.1111/j.1532-5415.2010.03127.x

[48] Kathleen Mikkelsen, Lily Stojanovska, Momir Polenakovic, Marijan Bosevski, and Vasso Apostolopoulos. 2017. Exercise and mental health. Maturitas 106 (2017), 48 - 56. https://doi.org/10.1016/j.maturitas.2017.09.003

[49] Vivian Genaro Motti and Kelly Caine. 2015. Users' Privacy Concerns About Wearables. In Financial Cryptography and Data Security, Michael Brenner, Nicolas Christin, Benjamin Johnson, and Kurt Rohloff (Eds.). Springer Berlin Heidelberg, Berlin, Heidelberg, 231-244.

[50] Alan F. Newell and Peter Gregor. 2000. "User Sensitive Inclusive Design" - in Search of a New Paradigm. In Proceedings on the 2000 Conference on Universal Usability (Arlington, Virginia, USA) (CUU '00). Association for Computing Machinery, New York, NY, USA, 39-44. https://doi.org/10.1145/355460.355470

[51] NHS. 2016. Health Survey for England: Adult overweight and obesity. https://digital.nhs.uk/data-and-information/ publications/statistical/health-survey-for-england/health-survey-for-england-2016.

[52] US Department of Health Services and Human. 2016. Physical Activity Guidelines for Americans. Technical Report. https://health.gov/PAGuidelines.

Proc. ACM Hum.-Comput. Interact., Vol. 5, No. CSCW1, Article 85. Publication date: April 2021. 
[53] Stefanie Painter, Gary Ditsch, Rezwan Ahmed, Nicholas Buck Hanson, Kevin Kachin, and Jan Berger. 2016. Retrofit Weight-Loss Outcomes at 6, 12, and 24 Months and Characteristics of 12-Month High Performers: A Retrospective Analysis. FMIR Mhealth Uhealth 4, 3 (22 Aug 2016), e101. https://doi.org/10.2196/mhealth.5873

[54] Andrea Parker, Vasudhara Kantroo, Hee Rin Lee, Miguel Osornio, Mansi Sharma, and Rebecca Grinter. 2012. Health Promotion as Activism: Building Community Capacity to Effect Social Change. In Proceedings of the SIGCHI Conference on Human Factors in Computing Systems (Austin, Texas, USA) (CHI '12). Association for Computing Machinery, New York, NY, USA, 99-108. https://doi.org/10.1145/2207676.2207692

[55] Josée Poirier, Wendy L Bennett, Gerald J Jerome, Nina G Shah, Mariana Lazo, Hsin-Chieh Yeh, Jeanne M Clark, and Nathan K Cobb. 2016. Effectiveness of an Activity Tracker- and Internet-Based Adaptive Walking Program for Adults: A Randomized Controlled Trial. f Med Internet Res 18, 2 (09 Feb 2016), e34. https://doi.org/10.2196/jmir.5295

[56] Neil Postman. 1985. Amusing Ourselves to Death. Penguin, Harmondsworth, England.

[57] Kimberly C. Preusse, Tracy L. Mitzner, Cara Bailey Fausset, and Wendy A. Rogers. 2017. Older Adults' Acceptance of Activity Trackers. Journal of Applied Gerontology 36, 2 (2017), 127-155. https://doi.org/10.1177/0733464815624151 arXiv:https://doi.org/10.1177/0733464815624151

[58] P. Rasche, M. Wille, S. Theis, K. Schäefer, C. M. Schlick, and A. Mertens. 2015. Activity Tracker and Elderly. In 2015 IEEE International Conference on Computer and Information Technology; Ubiquitous Computing and Communications; Dependable, Autonomic and Secure Computing; Pervasive Intelligence and Computing. IEEE, Liverpool, UK, 1411-1416.

[59] Toni Robertson and Ina Wagner. 2013. Engagement, representation and politics-in-action. The Handbook of Participatory Design, edited by J. Simonsen and T. Robertson. , 64-85 pages.

[60] Marcela D. Rodriguez, Jose R. Roa, Alberto L. Moran, and Sandra Nava-Munoz. 2012. Persuasive Strategies for Motivating Elders to Exercise. Proceedings of the 6th International Conference on Pervasive Computing Technologies for Healthcare (PervasiveHealth) and Workshops. , 219-223 pages.

[61] Richard M. Ryan and Edward L. Deci. 2000. Intrinsic and Extrinsic Motivations: Classic Definitions and New Directions. Contemporary Educational Psychology 25, 1 (2000), 54 - 67. https://doi.org/10.1006/ceps.1999.1020

[62] Herman Saksono, Carmen Castaneda-Sceppa, Jessica Hoffman, Magy Seif El-Nasr, Vivien Morris, and Andrea G. Parker. 2019. Social Reflections on Fitness Tracking Data: A Study with Families in Low-SES Neighborhoods. In Proceedings of the 2019 CHI Conference on Human Factors in Computing Systems (Glasgow, Scotland Uk) (CHI '19). Association for Computing Machinery, New York, NY, USA, Article 313, 14 pages. https://doi.org/10.1145/3290605.3300543

[63] Deborah A. Salem, G. Anne Bogat, and Christina Reid. 1997. Mutual help goes on-line. fournal of Community Psychology 25, 2 (1997), 189-207. https://doi.org/10.1002/(SICI)1520-6629(199703)25:2<189::AID-JCOP7>3.0.CO;2-T

[64] Anna Schlomann, Katja von Storch, Peter Rasche, and Christian Rietz. 2016. Means of Motivation or of Stress? The Use of Fitness Trackers for Self-Monitoring by Older Adults. HBScience 7 (2016), 111-116. https://doi.org/10.1007/s16024016-0275-6

[65] Karen A. Schutzer and B.Sue Graves. 2004. Barriers and motivations to exercise in older adults. Preventive Medicine 39 , 5 (2004), 1056 - 1061. https://doi.org/10.1016/j.ypmed.2004.04.003

[66] Leah M. Scolere, Eric P.S. Baumer, Lindsay Reynolds, and Geri Gay. 2016. Building Mood, Building Community: Usage Patterns of an Interactive Art Installation. In Proceedings of the 19th International Conference on Supporting Group Work (Sanibel Island, Florida, USA) (GROUP '16). Association for Computing Machinery, New York, NY, USA, 201-212. https://doi.org/10.1145/2957276.2957291

[67] Alexander Seifert, Anna Schlomann, Christian Rietz, and Hans Rudolf Schelling. 2017. The use of mobile devices for physical activity tracking in older adults' everyday life. DIGITAL HEALTH 3 (2017), 2055207617740088. https: //doi.org/10.1177/2055207617740088

[68] Anika Steinert, Marten Haesner, Aileen Tetley, and Elisabeth Steinhagen-Thiessen. 2016. Self-Monitoring of HealthRelated Goals in Older Adults with Use of a Smartphone Application. Activities, Adaptation \& Aging 40, 2 (2016), 81-92. https://doi.org/10.1080/01924788.2016.1158569

[69] Ann Taket, Beth R. Crisp, Annemarie Nevill, Greer Lamaro, Melissa Graham, and Sarah Barter-Godfrey. 2009. Theorising Social Exclusion. Routledge, 2 Park Square, Abingdon, Oxford, UK

[70] Nick Taylor and Keith Cheverst. 2010. Creating a Rural Community Display with Local Engagement. In Proceedings of the 8th ACM Conference on Designing Interactive Systems (Aarhus, Denmark) (DIS '10). Association for Computing Machinery, New York, NY, USA, 218-227. https://doi.org/10.1145/1858171.1858209

[71] Nick Taylor, Justin Marshall, Alicia Blum-Ross, John Mills, Jon Rogers, Paul Egglestone, David M. Frohlich, Peter Wright, and Patrick Olivier. 2012. Viewpoint: Empowering Communities with Situated Voting Devices. In Proceedings of the SIGCHI Conference on Human Factors in Computing Systems (Austin, Texas, USA) (CHI '12). Association for Computing Machinery, New York, NY, USA, 1361-1370. https://doi.org/10.1145/2207676.2208594

[72] Warren G. Thompson, Carol L. Kuhle, Gabriel A. Koepp, Shelly K. McCrady-Spitzer, and James A. Levine. 2014 "Go4Life" exercise counseling, accelerometer feedback, and activity levels in older people. Archives of Gerontology and Geriatrics 58, 3 (2014), 314 - 319. https://doi.org/10.1016/j.archger.2014.01.004 
[73] Akke K [van der Bij], Miranda G.H Laurant, and Michel Wensing. 2002. Effectiveness of physical activity interventions for older adults: a review1 1The full text of this article is available via AJPM Online at www.elsevier.com/locate/ajpmonline. American fournal of Preventive Medicine 22, 2 (2002), 120 - 133. https: //doi.org/10.1016/S0749-3797(01)00413-5

[74] Tiffany C Veinot, Hannah Mitchell, and Jessica S Ancker. 2018. Good intentions are not enough: how informatics interventions can worsen inequality. Journal of the American Medical Informatics Association 25, 8 (05 2018), 1080-1088 https://doi.org/10.1093/jamia/ocy052 arXiv:https://academic.oup.com/jamia/article-pdf/25/8/1080/25430904/ocy052.pdf

[75] John Vines, Rachel Clarke, Peter Wright, John McCarthy, and Patrick Olivier. 2013. Configuring Participation: On How We Involve People in Design. In Proceedings of the SIGCHI Conference on Human Factors in Computing Systems (Paris, France) (CHI '13). Association for Computing Machinery, New York, NY, USA, 429-438. https: //doi.org/10.1145/2470654.2470716

[76] Jon Whittle. 2014. How Much Participation is Enough? A Comparison of Six Participatory Design Projects in Terms of Outcomes. In Proceedings of the 13th Participatory Design Conference: Research Papers - Volume 1 (Windhoek, Namibia) (PDC '14). Association for Computing Machinery, New York, NY, USA, 121-130. https://doi.org/10.1145/2661435. 2661445

[77] Rayoung Yang, Eunice Shin, Mark W. Newman, and Mark S. Ackerman. 2015. When Fitness Trackers Don't "Fit": EndUser Difficulties in the Assessment of Personal Tracking Device Accuracy. In Proceedings of the 2015 ACM International foint Conference on Pervasive and Ubiquitous Computing (Osaka, Japan) (UbiComp '15). Association for Computing Machinery, New York, NY, USA, 623-634. https://doi.org/10.1145/2750858.2804269

Received June 2020; revised October 2020; accepted December 2020 